\title{
Bleomycin in verrucous squamous cell carcinoma of the oesophagus
}

\author{
TOSHIHIRO SAKURAI* \\ M.D. \\ TERUO OMAE* \\ M.D. \\ KAZUHIRO KUME
}

TADAHIKO FUCHIGAMI*
M.D.
AKINORI IWASHITA $†$
M.D.

SHOZO ASANO§

M.D.

Departments of *Internal Medicine II, and †Pathology II, Faculty of Medicine, Kyushu University, Fukuok@ Japan and Institute of $\ddagger$ Gastroenterology, §Otolaryngology section, Matsuyama Red Cross Hospitat Matsuyama, Japan

\section{Summary}

A case of verrucous squamous cell carcinoma of the oesophagus treated with bleomycin is reported. Bleomycin brought prompt reduction of the tumour and relief of symptoms. There have been no previous reports on experience with anti-cancer agents for verrucous carcinoma of the oesophagus. Administration of bleomycin might be an effective treatment for verrucous carcinoma of the oesophagus.

KEY WORDS: verrucous squamous cell carcinoma, oesophagus, bleomycin.

\section{Introduction}

Verrucous carcinoma is a slowly growing but gradually invasive variant of squamous cell carcinoma (Ackerman, 1948; Goethals, Harrison and Devine, 1963; Kraus and Perez-Mesa, 1966). It occurs most commonly in the oral cavity, nose, larynx, glans penis, vulva, vagina and scrotum (Goethals et al., 1963).

Verrucous carcinoma of the oesophagus is extremely rare with only 8 cases being reported (Meyerowitz and Shea, 1971; Minielly et al., 1967; Parkinson, Haidak and McInerney, 1970; Sridhar, Zeskind and Rising, 1980).

Although operative procedure and radiation therapy are frequently applied for this disease, there have been no reports on experience with an anti-cancer agent.

This report describes a patient with verrucous carcinoma of the oesophagus treated with bleomycin.

Reprint requests to: Toshihiro Sakurai, M.D., Department of Internal Medicine II, Faculty of Medicine, Kyushu University, Maidashi 3-1-1, Higashi-ku Fukuoka 812, Japan.

\section{Case report}

A 78-year-old woman was admitted on April 1960 with progressive dysphagia for 2 months. She did n: smoke or drink alcoholic beverages.

Physical examination was unremarkable. Oesophageal roentgenograms showed a large cauliflogrer like tumour, measuring $10 \times 5 \mathrm{~cm}$ in diameter 1). On endoscopic examination, a grayish-red tufinour was encountered $15 \mathrm{~cm}$ from the upper incisors. The tumour was fungating and friable. Biopsy showed hyperkeratosis and the swollen rete pegs formed of well-differentiated squamous cells, and the lesign was interpreted as verrucous carcinoma. Comput tomographic (CT) scan revealed a large oesophage tumour extending to trachea and thyroid gland. The vascularity of the tumour was moderate.

Because an operative procedure did not see appropriate considering her age, she was treated with intravenous bleomycin. Within 3 weeks, she had marked relief of symptoms. Oesophageal roentgenograms two months after the start of treatment showed that the tumour had reduced in size, measuring $6 \times 33$ $\mathrm{cm}$ in diameter (Fig. 2).

Bleomycin was then discontinued to prevent side effects such as pulmonary fibrosis when the total dose administered was $150 \mathrm{mg}$. Six months later, the patient was free from the symptoms, but was then losid to follow-up.

\section{Discussion}

The verrucous squamous cell carcinoma is an exophytic, warty and cauliflower-like tumour. Hist@pathologically, this tumour is characterized by h perkeratosis and swollen peg-like columns of differe entiated squamous cells extending into muscle layet 


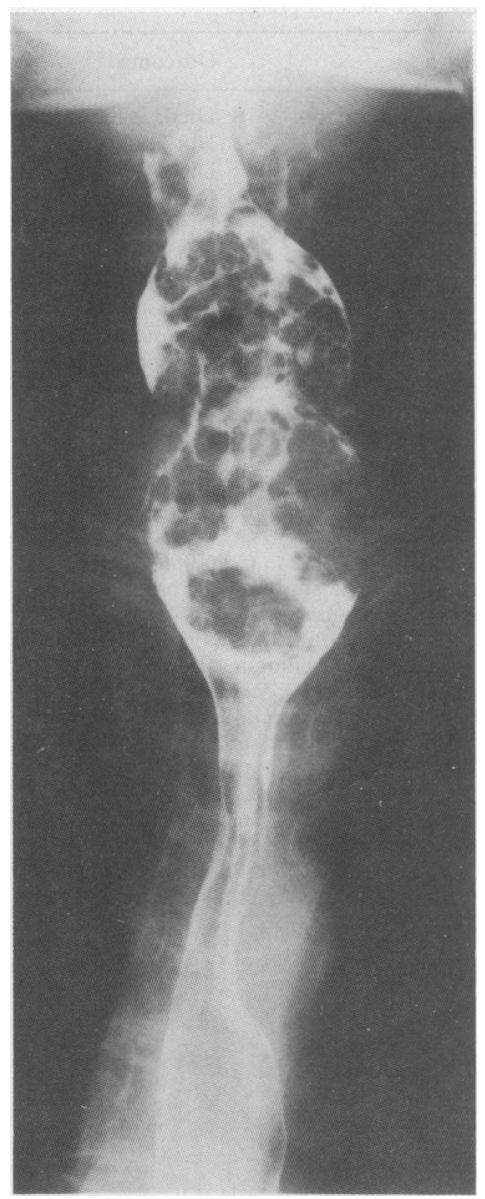

FiG. 1. Oesophageal roentgenograms on admission showing a large cauliflower-like tumour.

This lesion is a slowly growing, often extensive neoplasm that relentlessly invades local structure but rarely metastasizes (Goethals et al., 1963; Kraus and Perez-Mesa, 1966).

Nine cases with verrucous carcinoma of the oesophagus to date are listed in Table 1 . The average age is 60.7 years, similar to that of the usual types of oesophageal carcinoma. The predominant symptom is dysphagia present in 7 of the 9 patients. The tumour was situated in the upper third of the oesophagus in 4 of the 9 cases, whereas the usual type of oesophageal cancer is much less frequent at this site.

Surgical excision was performed in 4 cases, but the postoperative course was rather poor. The studies of verrucous carcinoma in other sites suggest that surgical therapy of those lesions has produced good results (Goethals et al., 1963; Kraus and Perez-Mesa,

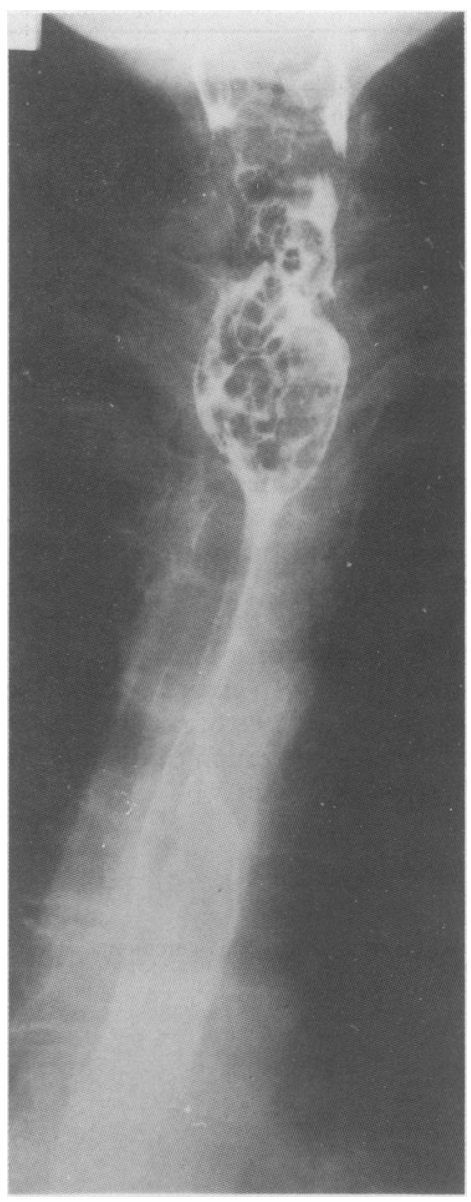

FIG. 2. Oesophageal roentgenograms after 2 months of administration of bleomycin. The tumour is reduced in size.

1966). The most important factor for this difference of postoperative course may be the low accessibility to surgical intervention for carcinoma of the oesophagus, compared with that of other sites. With development of surgical techniques, the operative mortality of the verrucous carcinoma of the oesophagus may be reduced.

According to the literature, radiation therapy alone does not seem advisable for verrucous carcinoma (Goethals et al., 1963; Kraus and Perez-Mesa, 1966). The response to this therapy is poor and there is a possibility that irradiation may change a low grade lesion into a much more anaplastic and aggressive one (Kraus and Perez-Mesa, 1966). Irradiation has been performed in 2 reported cases of oesophageal verrucous carcinoma, but the response to this therapy was poor.

There have been no reports on experience with 
TABLE 1. Reported cases of verrucous squamous carcinoma of the oesophagus

\begin{tabular}{lcllll}
\hline References & Age/sex & Symptoms & Site & Therapy & Outcome \\
\hline Minielly et al. (1967) & $58 \mathrm{M}$ & Dysphagia & U & Total oesophagectomy & Died, 35 days later \\
& $70 \mathrm{~F}$ & Dysphagia & U & Irradiation & Not known \\
& $70 \mathrm{~F}$ & Dysphagia & U & Irradiation & Died, 2 months later \\
& $36 \mathrm{M}$ & Dysphagia & L & Oesophagogastrectomy & Died, 6 weeks later \\
& $57 \mathrm{M}$ & Dysphagia & L & Supportive therapy & Died, 5 months later \\
Parkinson et al. (1971) & $76 \mathrm{M}$ & Weight loss & $\mathrm{M}$ & Supportive therapy & Died on 6 hospital day \\
Meyerowitz and Shea (1971) & $45 \mathrm{M}$ & Haematemesis & L & Oesophagogastrectomy & Died, 8 months later \\
Sridhar et al. (1980) & $54 \mathrm{M}$ & Dysphagia & L Partial oesophagectomy & Not known \\
Present authors & $78 \mathrm{~F}$ & Dysphagia & U & Bleomycin & Tumour reduced in size. \\
& & & & & Well at 6 months \\
\hline
\end{tabular}

$\mathrm{U}=$ upper third; $\mathbf{M}=$ middle third $\mathbf{L}=$ lower third.

anti-cancer agents for oesophageal verrucous carcinoma. This is the first case report in which bleomycin was employed for the treatment of verrucous carcinoma of the oesophagus. Bleomycin brought prompt reduction in size of the tumour and the patient was relieved of symptoms for a long period. Because the postoperative course of verrucous carcinoma of the oesophagus and the results of radiation therapy seem unsatisfactory, administration of bleomycin might be a more effective treatment.

\section{References}

ACKeRMAN, L.V. (1948) Verrucous carcinoma of the oral cavity. Surgery, 23, 670 .
Goethals, P.L., Harrison, E.G., Jr \& Devine, K.D. (1969 Verrucous squamous carcinoma of the oral cavity. Americun Journal of Surgery, 106, 845.

KRAUS, F.T. \& PEREZ-Mesa, C. (1966) Verrucous carcinoma? Clinical and pathologic study of 105 cases involving oral caviR larynx, and genitalia. Cancer, 19, 26.

MEYEROWITZ, B.R. \& SHEA, L.T. (1971) The natural history of squamous verrucous carcinoma of the esophagus. Journal 8 Thoracic and Cardiovascular Surgery, 61, 646.

Minielly, J.A., HARRISON, E.G., Jr., FonTANA, R.S. \& PAYND W.S. (1967) Verrucous squamous cell carcinoma of the esophagut. Cancer, 20, 2078.

PARKInSON, A.F., HAIDAK, G.L. \& MCINERNEY, R.P. (1979 Verrucous squamous cell carcinoma of the esophagus followi g lye stricture. Chest, 57, 489.

SRIDHAR, J.A., Zeskind, H.J. \& Rising, J.A. (1980) Verrucou squamous-cell carcinoma: An unusual tumor of the esophag\&. Radiology, 136, 614.

(Accepted 29 December 1982) 